\title{
Early postnatal protein malnutrition impairs recognition memory in rats (Rattus norvegicus)
}

\author{
Natalia Nassiff Braga, Marisa Tomoe Hebihara Fukuda, and Sebastião Sousa Almeida \\ Universidade de São Paulo, Ribeirão Preto, SP, Brasil
}

\begin{abstract}
The initial period of postnatal life is critical for brain development in both rodents and humans. Protein malnutrition imposed during this period produces irreversible consequences that include structural, neurochemical, and functional changes in the central nervous system, leading to long-term alterations in behavioral and cognitive parameters, such as memory. In this work, previously malnourished rats were evaluated in recognition memory procedures. Male Wistar rats $(n=132)$ were given isocaloric diets that contained 6\% (malnourished) or 16\% (control) protein until 49 days of life. A nutritional recovery period with standard lab chow was imposed from 50 to 70 days of age when the experiments began. Four different procedures of recognition memory were conducted. The analysis showed that malnourished rats had lower body weight compared with control rats from the first week of life until the end of the experiments $(p<.05)$. In the memory procedures, malnourished rats had lower recognition indices compared with controls $(p<.05)$. Well-nourished rats had a tendency to direct their exploration toward novelty, whereas malnourished rats explored the objects in the same proportion, demonstrating that they did not recognize the novelty. Protein malnutrition imposed early in life is suggested to affect hippocampal formation, the development of which is concentrated during this developmental period, and thus impair memory consolidation. Keywords: malnutrition, protein, recognition memory, learning, behavior.
\end{abstract}

Received 20 May 2013; received in revised form 11 November 2013; accepted 11 November 2013. Available online 28 April 2014.

\section{Introduction}

Malnutrition has been extensively studied because it causes changes in physical development in addition to maturational events in the brain that can result in memory, learning, and behavior impairments (Alamy \& Bengelloun, 2012). Among several types of malnutrition, protein malnutrition has received special attention because of its serious effects in which protein intake deficits reduce the amount of amino acids required for structural protein synthesis, enzymes, neuropeptides, and neurotransmitters (Almeida, Tonkiss, \& Galler, 1996; Diaz-Cintra, González-Maciel, Morales, Aguilar, Cintra, \& Prado-Alcalá, 2007; Hernández et al., 2008; Soares, Oliveira, Marchini, Antunes-Rodrigues, Elias, \& Almeida, 2013). Furthermore, the effects of

Natalia Nassiff Braga and Sebastião Sousa Almeida, Laboratório de Nutrição e Comportamento, Departamento de Psicologia, Faculdade de Filosofia, Ciências e Letras de Ribeirão Preto, Universidade de São Paulo. Marisa Tomoe Hebihara Fukuda, Departamento de Oftalmologia, Otorrinolaringologia e Cirurgia de Cabeça e Pescoço, Faculdade de Medicina de Ribeirão Preto, Universidade de São Paulo. Correspondence regarding this article should be directed to: Natália Nassiff Braga, Laboratório de Nutrição e Comportamento, Departamento de Psicologia, FFCLRP-USP, Avenida Bandeirantes, 3900, Ribeirão Preto, SP, 14040-901, Brasil. Fax: +55 16 36335015. E-mail: natalia.nassif@usp.br malnutrition may be exacerbated if it occurs during a critical period of brain development (i.e., the period during which the brain undergoes rapid growth and early maturational processes, such as cell proliferation, migration, and differentiation synaptogenesis, and gliogenesis (Dobbing, 1968; Rice, \& Barone, 2000). Among the brain regions most affected by malnutrition in early life, the hippocampus, a medial temporal lobe region, has been widely studied for its importance in the acquisition and consolidation of memory, thus playing a crucial role in learning (Lister et al., 2006; Hernández et al., 2008; Matos, Orozco-Solis, Lopes de Souza, Manhaes-e-Castro, \& Bolanos-Jimenez, 2011).

A memory system is defined as the way the brain processes information that will be available for later use. Thus, some of these systems are related to explicit memories that can be consciously evoked, defined as declarative memory, whereas other systems support implicit memories (i.e., those that cannot be evoked consciously), defined as non-declarative memory (O'Keefe \& Nadel, 1978). Declarative memory is subdivided into episodic memory, which refers to memories of specific events, and semantic memory, which is related to general aspects of an event (O'Keefe, \& Nadel, 1978; Manns, \& Eichenbaum, 2009).

Episodic memory processing depends on structures within the medial temporal lobe, particularly the 
hippocampus, the integrity of which is related to the ability to recall events related to spatial or nonspatial memories (Steckler, Drinkenburg, Sahgal, \& Aggleton, 1998; Eichenbaum, \& Fortin, 2009; Wilson, Langston, Schlesiger, Wagner, Watanabe, \& Ainge, 2013). Thus, among the several functions attributed to the hippocampus, one theory supports a cognitive map of the outside world that is part of a memory system that contains information about the location of the organism in the environment and its spatial relationship, in addition to the existence of specific items in specific locations (Steckler et al., 1998; Manns, Hopkins, Reed, Kitchener, \& Squire, 2003; Langston \& Wood, 2010; Barker \& Warburton, 2011; Levcik, Nekovarova, Stuchlik \& Klement, 2013).

Recognition memory is one example of episodic memory, which is characterized by a neural process whereby the subject is aware that a stimulus was previously encountered, which makes recognition a behavioral property of the process (Berlyne, 1950; Ennaceur \& Delacour, 1988). This type of memory requires that specific features of a given event are identified, discriminated, and compared with the characteristics of memories previously experienced (Ennaceur \& Delacour, 1988).

Experimental studies of recognition memory have conducted tests using the open field, a procedure in which the animal enters a different environment than the one to which it was habituated to explore new and known objects. These tests are based on the spontaneous preference of rats to explore novelty, which is attributable to the fact that the memory of the objects previously found was stored by the animal. Thus, this memory is evoked at the time of recognition, favoring the exploration of new elements (Clark, Zola, \& Squire, 2000; Mumby, Gaskin, Glenn, Schramek, \& Lehmann, 2002).

Several studies suggested that lesions of the hippocampus may affect recognition memory in which lesioned animals explore new and familiar objects in equal proportions (Rossato, Bevilaqua, Myskiw, Medina, Izquierdo, \& Cammarota, 2007; Langston \& Wood, 2010; Caceres et al., 2010; Broadbent, Gaskin, Squire, \& Clark, 2010). Early malnutrition is an event that impairs the proper formation of the hippocampal region, but few studies have analyzed the performance of malnourished animals in tests that involve recognition memory.

Thus, the objective of the present study was to analyze the performance of malnourished rats in several procedures that involve object recognition memory.

\section{Methods}

\section{Subjects}

Male Wistar rats $(n=136)$ from the animal colony of the University of São Paulo, Ribeirão Preto Campus, Brazil, were used. The methodology of this study was consistent with the ethical principles for animal experimentation and approved by the Ethics Committee for Animal Use. The litters $(n=35)$ consisted of the dam and six male and two female pups that were received on the day of birth and housed in the colony of the Laboratory of Nutrition and Behavior, University of São Paulo. The litters were divided according to their nutritional status, and the dams received powdered isocaloric diets with $6 \%$ protein (malnourished [M] group) or $16 \%$ protein (control [C] group) during the lactation period (0-21 days). It was necessary to use 22 litters of control animals and 13 litters of malnourished animals to achieve the required number of subjects because the high mortality rate caused by the severity of the malnutrition model. No more than two animals from each litter were assigned to each treatment group in each test condition. The powdered diets followed AIN-93 standards (Reeves, Nielsen, \& Fahey, 1993) and were prepared in accordance with modifications described by Santucci, Daud, Almeida, \& de Oliveira (1994; Table 1).

Table 1. Composition of control (C) and malnourished (M) isocaloric powdered diets (\%).

\begin{tabular}{lll}
\hline Components & Control (C) & Malnourished $(\mathbf{M})$ \\
\hline Protein (casein) & 16.0 & 6.0 \\
L-methionine & 0.032 & 0.012 \\
Corn oil & 8.0 & 8.0 \\
Salt mixture & 5.0 & 5.0 \\
Vitamin mixture & 1.0 & 1.0 \\
Choline & 0.2 & 0.2 \\
Cornstarch & 69.768 & 79.788 \\
\hline
\end{tabular}

Suppliers: Casein, L-methionine, salt and vitamin mixtures, and choline: Rhoster, Brazil. Corn oil and cornstarch: Mazola, Refinarias de Milho, Brazil

During lactation, the litters were housed in polypropylene cages $(41 \times 40 \times 17 \mathrm{~cm})$ covered with wood shavings. Weaning occurred on day 21 and consisted of the separation of the dam and female pups that were not used in the study to avoid possible variations related to the estrous cycle. Males were divided into groups of three and were housed in the cages described above.

After weaning, the rats received the control or lowprotein diet according to their initial condition (M or $\mathrm{C}$ ) until day 49 of life.

Nutritional recovery began on day 49 , with the replacement of the experimental diets with ad libitum standard laboratory chow (Nuvital Nutrients Ltda, Colombo, PR, Brazil) for all of the animals until day 70 when the behavioral tests began. The animals were maintained on a $12 \mathrm{~h} / 12 \mathrm{~h}$ light/dark cycle (lights on at 7:00 AM) with the room temperature kept at $22-24^{\circ} \mathrm{C}$. The experiments were conducted during the light phase of the light/dark cycle.

The dam and offspring were weighed during lactation on days 0 (birth), 7, 14, and 21. After weaning, the animals were weighed individually once per week until day 70 . 


\section{Apparatus}

All of the experiments were conducted in a square wooden open field that measured $1 \mathrm{~m} \times 1 \mathrm{~m} \times 1 \mathrm{~m}$ with the floor divided into nine equal squares. In Procedure 3 of Experiment 2, a circular open field $(60 \mathrm{~cm}$ diameter, $50 \mathrm{~cm}$ height) was also used. The devices were kept in rooms that were free of noise and had controlled lighting. They were used for recognizing identical copies of differently shaped objects made from various materials, such as plastic, glass, ceramic, and rubber. All of the objects followed standard sizes, textures, and materials used for this kind of experiment (Good, Barnes, Staal, McGregor, \& Honey, 2007; Akkerman et al., 2012; Dumont \& Aggleton, 2013).

In all of the experiments, the objects and their positions in the apparatus were presented in a counterbalanced manner. For example, half of the animals were exposed to object " $A$ " in the right corner of the arena as the novel stimulus, and the other half of the animals were exposed to object " $\mathrm{B}$ " in the left corner of the arena as the novel stimulus.

In each trial, the objects and open fields were cleaned with cotton soaked with $30 \%$ alcohol solution to eliminate odors. A Sony Handycam camera connected to a video system and monitor (both LG) was fixed above the open field. The video system and monitor were installed in an adjacent room to record the images that were subsequently analyzed using X-Plot Rat 2005 software.

\section{Procedures}

\section{Experiment 1}

Seventy-eight animals were tested in the first experiment. A square open field was used that contained a marble (Object A) and plastic domino piece (Object B) as the objects to be recognized by the animals. Over 3 consecutive days, the animals were subjected to habituation sessions that consisted of exploring the empty open field for 15 min daily. After the habituation period, the acquisition phase was conducted, during which the animal was placed in the open field in the presence of one of the objects located in one of the far corners of the arena. The animal was allowed to freely explore the arena for $10 \mathrm{~min}$. The animals were then divided into independent groups of two intervals (3 or $24 \mathrm{~h}$ ). After the established delay, the animal was subjected to the test phase during which it explored the open field in the presence of both objects (an identical copy of Object A and Object B) located in the far corner of the arena (Figure 1A). The objects used for known and novel stimuli and the positions of the items in the arena were counterbalanced among the animals to avoid the preference for one object or one position that could interfere with the results. To exclude the possibility that the difference in the recognition index between groups could be attributable to deficits in the exploration of the object during the sample phase, the time spent exploring the object presented during this phase was analyzed.
Exploratory and locomotor activity was assessed by recording the number of rearings (i.e., when the animal stood on its hind legs) and number of squares crossed by the animal.

\section{Experiment 2}

Fifty-eight different animals from the other experiment were used for Experiment 2. These animals were subjected to three procedures.

Procedure 1: Recognition memory for complex scenes. This procedure began the day after the end of the habituation phase (73-day-old animals). In the sample phase of this experiment, the animals were exposed to the open field that contained three of the following objects: a plastic ball (Object C), a plastic cone (Object D), a ceramic cup (Object E), and a plastic cube (Object F). The objects were always located in the right and left far corners of the arena and middle of the near side of the arena (Figure 1B), but the stimulus used as the novel item and its position (i.e., one of the three possible positions) were always counterbalanced among the subjects. The animals were exposed to this environment in five sessions of $5 \mathrm{~min}$ each, with 15 -min intervals between them. Twenty-four hours after the last exposure, the test phase was conducted, in which the animals were returned to the open field for $5 \mathrm{~min}$. The environment in this exposure contained two identical copies of the previously explored objects and an entirely new object. In the test phase, the period of time during which the animal explored each object was analyzed.

Procedure 2: Recognition memory for spatial locations. The second procedure began 3 weeks after Procedure 1 (95-day-old animals). For this procedure, two identical copies of square-shaped pieces of plastic were used. In the sample phase, the animals explored the objects (G1 and G2) arranged in the upper adjacent corners of the open field during five periods of $5 \mathrm{~min}$ each, with $15 \mathrm{~min}$ intervals between them (Figure 1C). After $24 \mathrm{~h}$, the test phase was conducted, and the animals were again placed in the open field with G1 in the original position and G2 located diagonally to G1 (i.e., G2 was placed in a different position than the location previously experienced by the animal). The period of time during which the animals explored objects G1 and $\mathrm{G} 2$ in the test phase was recorded.

Procedure 3: Recognition memory for contexts. The third procedure was initiated 3 weeks after Procedure 2 (116-day-old animals). Two environments were used with features that the animals could identify. These environments represented two different contexts ( $\mathrm{X}$ and $\mathrm{Y}$ ). In the $\mathrm{X}$ context, a square-shaped wooden open field with gray walls and a steel plate floor was used. In this environment, the lighting was 100 lux. In the Y context, the circular open field with blackand white-striped walls was used. The floor of the open field was littered with wood shavings, and the apparatus was placed in a different room with a light intensity of 30 lux. 
For recognition, two pairs of objects were used, with each pair consisting of identical objects. These objects were a pair of rubber triangles (Objects $\mathrm{H} 1$ and $\mathrm{H} 2$ ) and a pair of empty soda cans (Objects I1 and I2). Before testing the animals, a new habituation phase was implemented because this procedure was performed in different environments from those known by the animal. Thus, the animals underwent three daily sessions of habituation, each lasting $5 \mathrm{~min}$ in both environments without the objects.

This procedure consisted of two sample phases and a test phase. In sample phase 1, the animal was placed in one of the contexts for $5 \mathrm{~min}$ in the presence of one pair of objects (H1 and $\mathrm{H} 2$ or I1 and I2). After an interval of 5 min, sample phase 2 began, and the animal was exposed to the other context in the presence of the pair of objects that had not yet been explored. After another interval of 5 $\mathrm{min}$, the animal was placed in one of the contexts (X or Y) with one object that belonged to the context and another that belonged to the different context (H1 and I2 or I1 and H2; Figure 1D). The sequence of this experiment with regard to whether the animal began the sample phases with Context $\mathrm{X}$ or $\mathrm{Y}$ and whether the test phase was conducted with Context $\mathrm{X}$ or $\mathrm{Y}$ was always counterbalanced among the animals. The period of time during which the animal explored the objects during the test phase was recorded.

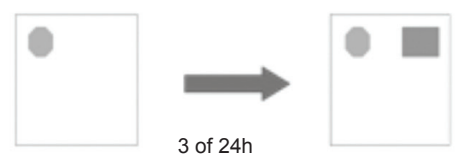

B
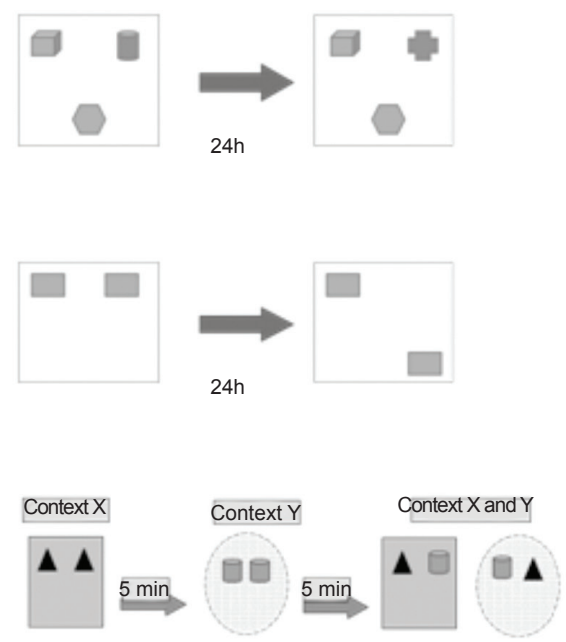

Figure 1. Schematics of recognition memory tests. (A) Schematic that illustrates one possibility of object arrangement in the far corners of the open field in Experiment 1. (B) Schematic that illustrates one possibility of object arrangement in Procedure 1 in Experiment 2 (i.e., recognition memory for complex scenes). (C) Schematic that illustrates Procedure 2 in Experiment 2 (i.e., recognition memory for spatial locations). (D) Schematic that illustrates one possibility of object arrangement in the contexts used in Procedure 3 in Experiment 2 (i.e., recognition memory for contexts).

\section{Statistical Analysis}

Exploration of the objects was considered to have occurred when the animal approached the objects at a distance of $\leq 5 \mathrm{~cm}$. All of the exploration times were recorded. These data were used to calculate the recognition index using the following formula: RI $=$ (time exploring novel object $/$ time exploring all objects) $\times 100$. In the procedures in Experiment 2, a minute-by-minute analysis of novel and all-object exploration was conducted to determine whether there were changes in the preference for objects during the test.

The animal weight data were analyzed using a twoway (diet condition $\times$ day of life) analysis of variance (ANOVA), with the day factor as the repeated measure. For the minute-by-minute analysis of the preference for the objects, a two-way (diet condition $\times$ minute) ANOVA was used, with the minute factor as the repeated measure. Post hoc comparisons were performed using the Newman-Keuls test.

The behavioral data, including the recognition index, object exploration in the acquisition phase, number of squares crossed, and number of rearings, were analyzed using the Student's $t$-test for independent samples. The level of significance was set at $p<.05$ in all of the analyses.

\section{Results}

\section{Body Weight}

Dams that were fed a malnourished diet $(6 \%)$ had greater weight loss in the lactation period. The ANOVA revealed significant effects of diet condition $\left(F_{1,10}=\right.$ $63.52, p<.001)$ and day of life $\left(F_{2,68}=14.99, p<.001\right)$ and a diet condition $\times$ day of life interaction $\left(F_{2,68}=\right.$ 17.6, $p<.001)$. The post hoc comparisons revealed that malnourished dams differed from controls in the first and second weeks of the lactation period $(p<.05$; Figure 2). When considering the entire lactation period, malnourished dams had greater cumulative weight loss compared with controls $(\mathrm{t} 21=8.35, \mathrm{p}<.05$; Figure 2$)$.

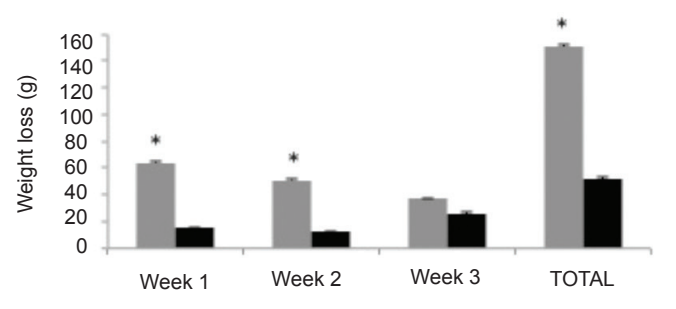

Figure 2. Weight loss in the dams during lactation. The figure shows weight loss in control $(\mathrm{C} ; n=13)$ and malnourished (M; $n=22$ ) dams during 3 weeks of lactation and cumulative weight loss (Total). The data are expressed as mean \pm SEM. $* p<.05$, compared with control dams in the same week (Newman-Keuls test). 
Malnourished litters had lower body weight than controls during the lactation period. The ANOVA revealed significant effects of diet condition $\left(F_{1,9}=\right.$ $140.9, p<.001)$ and day of life $\left(F_{3,27}=542.3, p<.001\right)$ and a diet condition $\times$ day of life interaction $\left(F_{3,27}=\right.$ $156.3, p<.001)$. The post hoc comparisons revealed that malnourished litters weighed less than controls on days $7,14$, and $21(p<.05)$. At birth (day 0$)$, no significant difference was found among the groups, demonstrating that all of the rats were in the same nutritional condition at the beginning of the treatment (Figure 3).

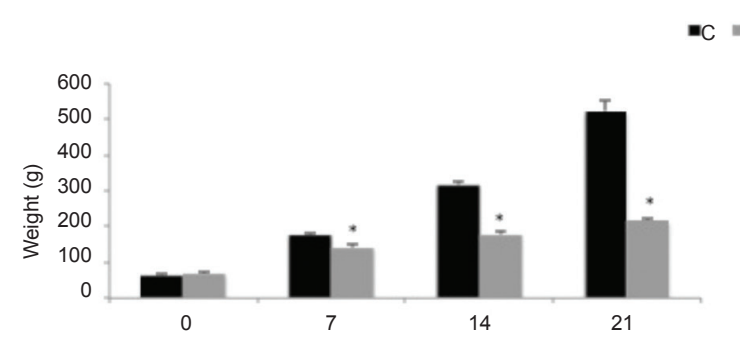

Figure 3. Body weight of the litters during lactation. The figure shows the body weight of control $(\mathrm{C} ; n=13)$ and malnourished $(\mathrm{M} ; n=22)$ litters during the lactation period. The data are expressed as mean \pm SEM. $* p<.05$, compared with control litters on the same day (NewmanKeuls test).

Body weight in the $\mathrm{M}$ group was affected by the low-protein diet, and animals in the $\mathrm{C}$ group were heavier than animals in the $\mathrm{M}$ group, reflected by a significant effect of diet condition $\left(F_{1,60}=1012.9, p<\right.$ $.001)$. Animals in both groups exhibited a significant increase in body weight across days, demonstrated by a significant effect of day of life $\left(F_{6,360}=2913.1, p<\right.$ $.001)$. However, the $\mathrm{C}$ group had a greater increase than the $\mathrm{M}$ group, reflected by a significant diet condition day of life interaction $\left(F_{6,360}=389.2, p<.001\right.$; Figure 4$)$.

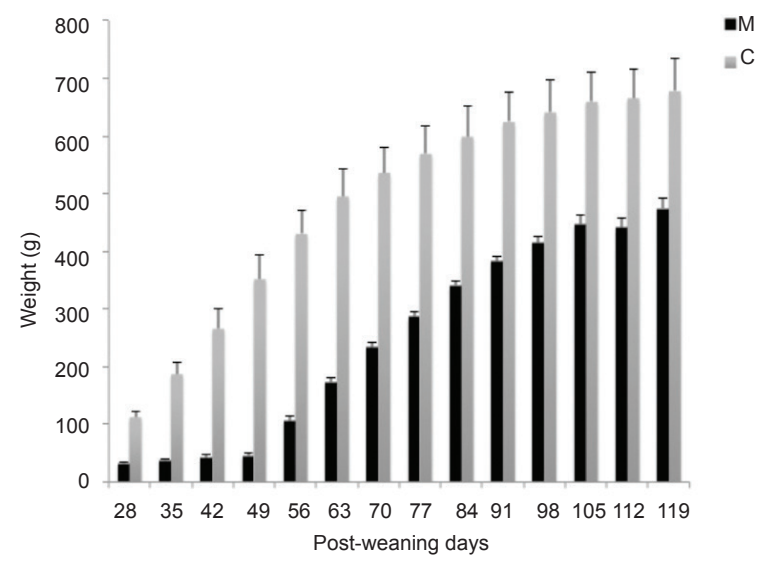

Figure 4. Body weight of post-weaning rats. The figure shows the body weight of control $(\mathrm{C} ; n=70)$ and malnourished $(\mathrm{M}$; $n=66$ ) rats from 28 days of life (post-weaning) until day 119 . The data are expressed as mean \pm SEM. ${ }^{*} p<.05$ compared with control animals (Newman-Keuls test).
Malnourished animals had a greater mortality index compared with controls. During the period of analysis, the mortality index was $50 \%$ in malnourished animals and $10.25 \%$ in control animals.

The exploration of Object $A$ in the sample phase in Experiment 1 was not different between groups, demonstrating that the $\mathrm{C}$ and $\mathrm{M}$ groups exhibited similar exploration during this sample phase.

In the test phase in Experiment 1, significant differences in the recognition indices were observed between the $\mathrm{C}$ and $\mathrm{M}$ groups within the $3 \mathrm{~h}$ interval $\left(t_{38}=2.87, p<.05\right)$ and $24 \mathrm{~h}$ interval $\left(t_{36}=2.34, p<\right.$ $.05)$. This difference showed that the $\mathrm{C}$ group had a higher recognition index than the $\mathrm{M}$ group (Figure 5), regardless of the interval between the sample and test phases. No differences were found with regard to the number of squares crossed or rearings.

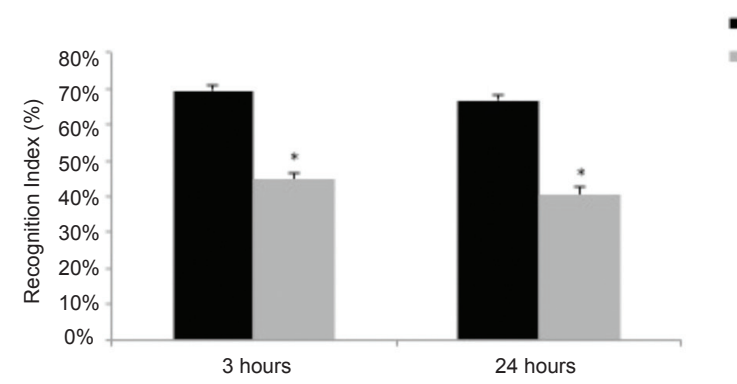

Figure 5. Experiment 1: Recognition index for novel objects. The recognition index for novel objects in control (C) and malnourished (M) animals was calculated at 3 and $24 \mathrm{~h}$ intervals. The data are expressed as mean \pm SEM (Control: $n=$ 24 and 23 for 3 and $24 \mathrm{~h}$ intervals, respectively; Malnourished: $n=16$ and 15 for 3 and 24 h intervals, respectively). ${ }^{*} p<.05$ compared with control animals.

In all of the recognition memory procedures performed in Experiment 2, the animals in Group $\mathrm{M}$ had lower recognition indices compared with the $\mathrm{C}$ group (Procedure 1: $t_{56}=2.78, p<.05$; Procedure 2: $t_{58}=2.67, p<.05$; Procedure $3: t_{51}=3.18, p<.05$; Figure 6-8).

The minute-by-minute analysis of the exploration of novel objects and exploration of all of the objects conducted for the procedures in Experiment 2 showed no effect of diet condition, although a significant effect of the minute factor was observed in the analysis of the exploration of novel objects (Procedure 1: $F_{4,224}=6.77$, $p<.05$; Procedure 2: $F_{4,232}=4.02, p<.05$; Procedure 3: $\left.F_{4,204}=23.68, p<.05\right)$ and exploration of all of the objects (Procedure 1: $F_{4,224}=7.95, p<.05$; Procedure 2: $F_{4,232}=7.11, p<.05$; Procedure $3: F_{4,204}=16.73, p$ $<.05)$.

The effect of the minute factor showed that both the $\mathrm{C}$ and $\mathrm{M}$ groups exhibited a decrease in object exploration during the test. This demonstrated that the groups habituated to the objects during the test, regardless of their nutritional condition. 


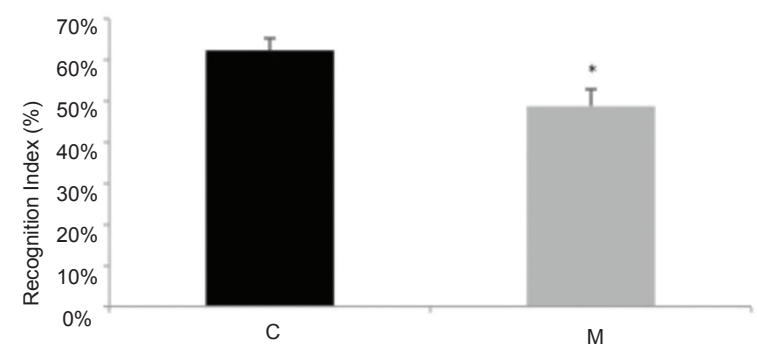

Figure 6. Experiment 2, Procedure 1: Recognition index for complex scenes. The recognition index for complex scenes was calculated in control $(\mathrm{C} ; n=23)$ and malnourished (M; $n$ $=35)$ animals. The data are expressed as mean \pm SEM. $* p<$ .05 compared with control animals.

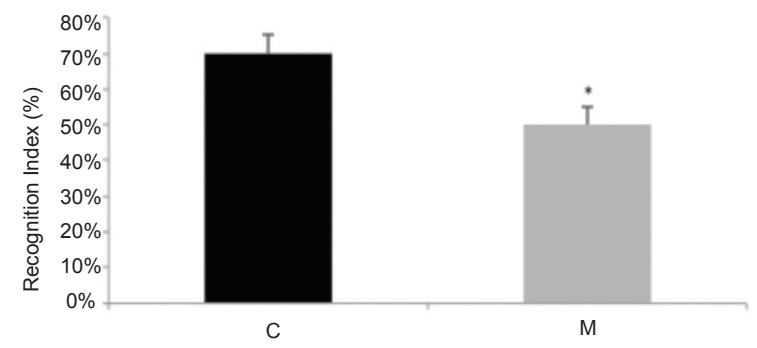

Figure 7. Experiment 2, Procedure 2: Recognition index for spatial locations. The recognition index for spatial locations was calculated in control $(\mathrm{C} ; n=23)$ and malnourished $(\mathrm{M} ; n$ $=35$ ) animals. The data are expressed as mean \pm SEM. ${ }^{*} p<$ .05 compared with control animals.

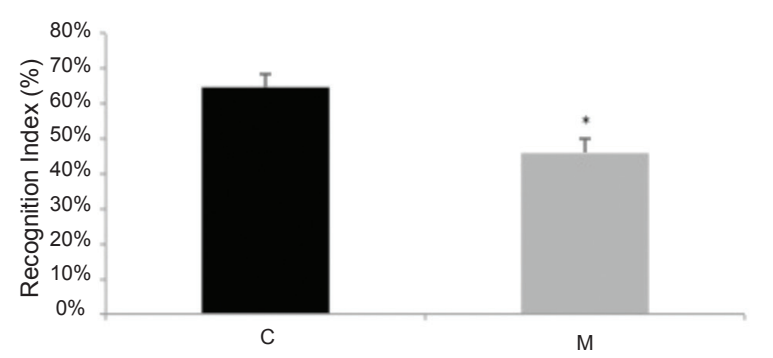

Figure 8. Experiment 2, Procedure 3: Recognition index for contexts. The recognition index for contexts was calculated in control $(\mathrm{C} ; n=23)$ and malnourished $(\mathrm{M} ; n=35)$ animals. The data are expressed as mean \pm SEM. ${ }^{*} p<.05$ compared with control animals.

\section{Discussion}

The evaluation of weight loss in dams confirmed the effects produced by the nutritional treatment because both groups were in the same nutritional condition at the beginning of the treatment. Consumption of the protein-deficient diet during the lactation period caused the greatest weight loss in the dams, whereas weight loss was less in the control group. The lactation period demands high energy expenditures caused by maternal care of the pups and milk production. Energy expenditure, combined with the deficient intake of protein, does not supply the necessary amount of amino acids required for body maintenance, thus causing accentuated weight loss during this period. This fact was more moderate in control dams that also expended energy, but this expenditure was offset by the ingestion of a nutritionally adequate diet (Cambraia, Vannucchi, \& De-Oliveira, 1997). In the third week of the lactation period, both groups had similar weight loss. This could be attributable to the reduction of breastfeeding at this age because the pups already feed on the diet available in the cage.

Malnourished animals had lower body weight compared with control animals throughout the study period. Even after nutritional recovery, despite an increase in body weight, malnourished rats did not reach the average weight gain of control rats. This weight difference persisted into adulthood and can be explained by the fact that body weight in adult animals is determined during the pregnancy and lactation periods (Passos, Ramos, \& Moura, 2000) in which the weight of adult animals depends on the nutritional conditions that exist during these periods. In the present study, the animals were exposed to a low-protein diet from lactation to 49 days of life, resulting in lower weight gain compared with controls. These data are consistent with previous studies, demonstrating that rats subjected to malnutrition during early postnatal periods are unable to achieve the weight of the control group, even after a nutritional recovery period (Prestes-Carneiro, Laraya, Silva, Moliterno, Felipe, \& Mathias, 2006; Valadares, Fukuda, Françolin-Silva, Hernandes, \& Almeida, 2010).

In addition to changes in body weight, early protein malnutrition can produce long-term effects on brain systems that regulate behavior. These changes can impact brain systems that play an important role in learning and memory processes (Galler, Shumsky, \& Morgane, 1995; Lukoyanov, \& Andrade, 2000; Lister et al., 2006; Hernández et al., 2008; Matos et al., 2011) such as the hippocampal formation. The integrity of this system is crucial for the retention of certain types of information, including information related to recognition memory (Clark et al., 2000; Mumby et al., 2002; Ergorul \& Eichenbaum, 2004; O'Brien, Lehmann, Lecluse, \& Mumby, 2006; Rossato et al., 2007; Langston \& Wood, 2010; Caceres et al., 2010; Broadbent et al., 2010).

This classic episodic memory task covers different phases (Suzuki \& Eichenbaum, 2000). The stimulus is first presented. A delay then occurs, during which the subject needs to retain the representation of what was seen. After this delay, a different situation is presented, in which the subject retrieves the representation stored in memory and confronts the new situation. In rats, during this last phase they always present spontaneous preference for novelty (Ennaceur \& Delacour 1988), but this is only able to occur if the subject can appropriately discriminate which stimuli were new and which stimuli were previously known.

In all of the procedures of recognition memory analyzed in this work, independent of the delay between the sample and test phases, malnourished rats did not 
differentiate between the known and novel stimuli. They explored all of the situations in the same proportions, suggesting that malnourished rats could not retain the information about the objects during the acquisition phase and delay. Thus, the rats were unable to process the information to determine which was novel.

Rat studies have reported the neural pathways associated with episodic memory (Morgan-Zola, \& Squire, 1993; Suzuki, \& Eichenbaum, 2000). Recognition memory signals can be seen in the hippocampal formation, more markedly in the CA1 area (Suzuki \& Eichenbaum, 2000, Izquierdo, 2011), reflected by neuronal activation. These kinds of signals can be seen in hippocampus-adjacent cortices such as the entorhinal, perirhinal, frontal, and parietal cortices (Morgan-Zola \& Squire, 1993; Suzuki \& Eichenbaum, 2000; Izquierdo, 2011).

Malnutrition is known as an environmental event that affects the global development of the brain if it occurs early in life. It can alter the activity of enzymes, thus interfering with protein synthesis in several brain structures (Alamy \& Bengelloun, 2012). Among all of the structures involved in the consolidation of memory, the development of the hippocampal formation is concentrated during the postnatal period (Bayer, 1980). Therefore, an episode of protein malnutrition during this phase can lead to structural changes that can permanently affect memory consolidation.

The present behavioral findings suggest that the hippocampal formation was severely affected. No difference was found between the $\mathrm{C}$ and $\mathrm{M}$ groups in the acquisition phase in Experiment 1. This analysis was performed to determine whether the difference in the recognition indices in control and malnourished animals was attributable to deficits in the exploration of the object during this phase. However, the present data analysis revealed no significant differences between groups, excluding the possibility that the differences in recognition indices were attributable to exploration deficits during this phase.

Other evidence involves the fact that malnourished animals underwent nutritional recovery after the malnourishment insult. Although their body weight greatly increased, permanent impairment was observed in all of the memory tests, demonstrating that the addition of a standard amount of protein in their diet was insufficient to fully recover the cognitive deficits caused by malnutrition. The lack of protein during early stages of development appeared to cause malformation of brain structures, such as the hippocampal formation, that were in a growth phase during this period. After the developmental period, protein supplementation was insufficient to correct the malformation of the affected brain structures, thus leading to long-lasting changes. In accordance with this possibility, previous studies reported permanent behavioral changes in early-malnourished rats, even after nutritional recovery (Wolf, Almli, Finger, Ryan, \& Morgane, 1986; Valadares et al., 2010).
Interestingly, memory deficits caused by protein malnutrition are very similar to those caused by hippocampal lesions. Cumulative evidence has shown deficits in episodic memory in various recognition memory tasks caused by several types of lesions concentrated in hippocampal regions (Clark et al., 2000; Mumby et al., 2002; Manns et al., 2003; Broadbent, Squire \& Clark, 2004; Ainge, Heron-Maxwell, Theofilas, Wright, de Hoz, \& Wood, 2006; Gaskin, Tardif, Cole, Piterkin, Kayello, \& Mumby, 2010). We suggest that the similarity in cognitive performance in malnourished and lesioned animals is attributable to hippocampal impairment. Importantly, however, the hippocampal formation is not the only brain region that undergoes development during the early period in which malnutrition was imposed. Malnutrition likely affects other brain regions that can influence the consolidation and recall of memory such as cortical areas (Suzuki \& Eichenbaum, 2000). Further studies that analyze protein malnutrition-induced global impairments in brain areas involved in memory are needed.

In the present study, malnourished rats were unable to recognize novelty, even when the new aspect of an experiment was not an object per se but rather the environment or location where it was found. Dix \& Aggleton (1999) reported that rats recognized novelty when the variable between the acquisition and test phases was a modified position of the objects or an object located in a different context from where it was previously found. Malnourished animals exhibited no signs that indicated the recognition of the spatial change of the objects or recognition that a particular object was or was not associated with a certain context because they explored the objects located in the familiar and new positions/contexts for the same amount of time. In contrast, control animals were able to discriminate the novel features of the objects, showing high indices of recognition in all of the procedures. Again, our findings are consistent with other studies in the literature that showed that this type of memory is affected by damage to the hippocampal region (Mumby et al., 2002; Langston \& Wood, 2010).

The number of rearings and square crossings was recorded to exclude the possibility that changes in exploratory activity produced by malnutrition influenced the results. The present data showed that both control and malnourished animals exhibited similar exploratory activity, indicating that malnutrition did not affect this behavior. Previous studies have shown that nutritional treatments imposed in the early stages of life, together with the occurrence of nutritional recovery, did not affect locomotor or exploratory activity in malnourished animals in the elevated plus maze, which is consistent with the present data (Françolin-Silva, da Silva Hernandes, Fukuda, Valadares, \& Almeida, 2006).

The minute-by-minute analysis of the procedures in the second experiment revealed that both groups exhibited a reduction of exploration of both novel objects and other objects during the 5-min test. This 
finding is consistent with previous studies that indicated that separate minute-by-minute analysis of spontaneous preference for objects reveals an habituation curve in which the animals become accustomed to novelty during the test, even when they suffer some type of injury in the hippocampal formation (Dix \& Aggleton, 1999; Clark et al., 2000; Mumby, 2001; Mumby et al., 2002).

In summary, early protein malnutrition was responsible for the impaired performance of the rats in all of the recognition memory procedures. Protein malnutrition in rats, when imposed early in life, appears to impair the development of the hippocampal formation, a brain region directly related to episodic memory and, more specifically, recognition memory. Although malnourished rats underwent a period of nutritional recovery in the present study, they were unable to reach the recognition indices demonstrated by control animals. Thus, early protein malnutrition causes long-term impairments in recognition memory in rats.

\section{Acknowledgements}

We would like to thank Fundação de Amparo à Pesquisa do Estado de São Paulo (FAPESP) for financial support. N.N. Braga was a recipient of a fellowship from FAPESP (process no. 2008/01078-5).

\section{References}

Ainge, J.A., Heron-Maxwell, C., Theofilas, P., Wright, P., de Hoz, L., \& Wood, E.R. (2006). The role of the hippocampus in object recognition in rats: examination of the influence of tasks parameters and lesion size. Behavioural Brain Research, 167, 183-195.

Akkerman, S., Blockland, A., Reneerkens, O., van Goethem, N.P., Bollen, E., Gijselaers, H.J.M., ... \& Prickaerts J. (2012). Object recognition testing: methodological considerations on exploration and discrimination measures. Behavioral Brain Research, 232, 335347.

Alamy, M., \& Bengelloun, W.A. (2012). Malnutrition and brain development: an analysis of the effects of anadequate diet during different stages of life in rat. Neuroscience and Biobehavioral Reviews, 36, 1463-1480.

Almeida, S.S., Tonkiss, J., \& Galler, J.R. (1996). Prenatal protein malnutrition affects the social interactions of juvenile rats. Physiology and Behavior, 60(1), 197-201.

Barker, G.R.I., \& Warburton, E.C. (2011). When is the hippocampus involved in recognition memory? Journal of Neuroscience, 31(29), 10721-10731.

Bayer, S.A. (1980). Development of hippocampal region in the rat: II. Morphogenesis during embryonic and early postnatal life. Journal of Comparative Neurology, 190, 115-134.

Berlyne, D.E. (1950). Novelty and curiosity as determinants of exploratory behavior. British Journal of Psychology, 41, 68-80.

Broadbent, N.J., Gaskin, S., Squire, L.R., \& Clark, R.E. (2010). Object recognition memory and the rodent hippocampus. Learning and Memory, 17, 5-11.

Broadbent, N.J., Squire, L.R., \& Clark, R.E. (2004). Spatial memory, recognition memory, and the hippocampus. Proceedings of the National Academy of Sciences of the United States of America, 101(40), 14515-14520.

Caceres, L.G., Bertolino, L.A., Saraceno, G.E., Zorrilla Zubilete, M.A., Uran, S.L., Capani, F., \& Guelman, L.R. (2010). Hippocampal-related memory deficits and histological damage induced by neonatal ionizing radiation exposure: role of oxidative status. Brain Research, 1312, 67-78.
Cambraia, R.P.B., Vannucchi, H., \& De-Oliveira, L.M. (1997). Food intake and weight of lactating rats maintained on different proteincalorie diets, and pup growth. Brazilian Journal of Medical and Biological Research, 30, 985-988.

Clark, R.E., Zola, S.M., \& Squire, L.R. (2000). Impaired recognition memory in rats after damage to the hippocampus. Journal of Neuroscience, 20, 8853-8860.

Diaz-Cintra, S., González-Maciel, A., Morales, M.A., Aguilar, A., Cintra, L., \& Prado-Alcalá, R.A. (2007). Protein malnutrition differentially alters the number of glutamic acid decarboxylase- 67 interneurons in dentate gyrus and CA1-3 subfields of the dorsal hippocampus. Experimental Neurology, 208, 47-53.

Dix, S.L., \& Aggleton, J.P. (1999). Extending the spontaneous preference test of recognition: evidence of object-location and object-context recognition. Behavioural Brain Research, 99, 191200.

Dobbing, J. (1968). Vulnerable periods in developing brain. In: A.N. Davidson, \& J. Dobbing (Eds.), Applied neurochemistry (pp. 287316). Oxford: Blackwell Scientific.

Dumont, J.R., \& Aggleton, J.P. (2013). Dissociation of recognition and recency memory judgments after anterior thalamic nuclei lesions in rats. Behavioral Neuroscience, 127(3), 415-431.

Eichenbaum, H., \& Fortin, N.J. (2009) The neurobiology of memory based predictions. Philosophical Transactions of the Royal Society of London B: Biological Sciences, 364, 1183-1191.

Ennaceur, A., \& Delacour, J. (1988). A new one-trial test for neurobiological studies of memory in rats: 1 . Behavioral data. Behavioural Brain Research, 31, 47-59.

Ergorul, C., \& Eichenbaum, H. (2004). The hippocampus and memory for "what," "where," and "when." Learning and Memory, 11, 397-405.

Françolin-Silva, A.L., da Silva Hernandes, A., Fukuda, M.T.H., Valadares, C.T., \& Almeida, S.S. (2006). Anxiolytic-like effects on short-term postnatal protein malnutrition in the elevated plus-maze test. Behavioural Brain Research, 173, 310-314.

Galler, J.R., Shumsky, J.S., \& Morgane, P.J. (1995) Malnutrition and brain development. In: W.A. Walker, \& J.B. Watkins (Eds.), Nutrition in pediatrics: basic science and clinical applications (pp. 194-210). Philadelphia: B.C. Decker.

Gaskin, S., Tardif, M., Cole, E., Piterkin, P., Kayello, L., \& Mumby, D.G. (2010). Object familiarization and novel-object preference in rats. Behavioral Processes, 83, 61-71.

Good, M.A., Barnes, P., Staal, V., McGregor, A., \& Honey, R.C. (2007). Context- but not familiarity-dependent forms of object recognition are impaired following excitotoxic hipocampal lesions in rats. Behavioral Neuroscience, 121(1), 218-223.

Hernández, A., Burgos, H., Mondaca, M., Barra, R., Núñez, H., Pérez, H., ... \& Valladares, L. (2008). Effect of prenatal protein malnutrition on long-term potentiation and BDNF protein expression in the rat entorhinal cortex after neocortical and hippocampal tetanization. Neural Plasticity, 2008, 646919.

Izquierdo, I. (2011). Memória. Porto Alegre: Artmed.

Langston, R.F., \& Wood, E.R. (2010). Associative recognition and the hippocampus: differential effects of hippocampal lesions on object-place, object-context and object-place-context memory. Hippocampus, 20(10), 1139-1153.

Levcik, D., Nekovarova, T., Stuchlik, A., \& Klement, D. (2013). Rats use hippocampus to recognize positions of objects located in an inaccessible space. Hippocampus, 23, 153-161.

Lister, J.P., Tonkiss, J., Blatt, G.J., Kemper, T.L., DeBassio, W.A., Galler, J.R., \& Rosene, D.L. (2006). Asymmetry of neuron numbers in the hippocampal formation of prenatally malnourished and normally nourished rats: a stereological investigation. Hippocampus, 16(11), 946-958.

Lukoyanov, N.V., \& Andrade, J.P. (2000). Behavioral effects of protein deprivation and rehabilitation in adult rats: relevance to morphological alterations in the hippocampal formation. Behavioural Brain Research, 112, 85-97.

Manns, J.R., \& Einchenbaum, H. (2009). A cognitive map for object memory in the hippocampus. Learning and Memory, 16, 616-624.

Manns, J.R., Hopkins, R.O., Reed, J.M., Kitchener, E.G., \& Squire, L.R. (2003). Recognition memory and the human hippocampus. Neuron, 37, 171-180.

Matos, R.J.B., Orozco-Solis, R., Lopes de Souza, S., Manhaes-eCastro, R., \& Bolanos-Jimenez, F. (2011). Nutrient restriction 
during early life reduces cell proliferation in the hippocampus at adulthood but does not impair neuronal differentiation process of the new generated cells. Neuroscience, 196, 16-24.

Morgan-Zola, S., \& Squire, L.R. (1993). Neuroanatomy of memory. Annual Review of Neuroscience, 16, 547-563.

Mumby, D.G. (2001) Perspectives on object-recognition memory following hippocampal damage: lessons from studies in rats. Behavioural Brain Research, 127, 159-181.

Mumby, D.G., Gaskin, S., Glenn, M.J., Schramek, T.E., \& Lehmann, H. (2002). Hippocampal damage and exploratory preferences in rats: memory for objects, places, and contexts. Learning and Memory, 9, 49-57.

O’Brien, N., Lehmann, H., Lecluse, V., \& Mumby, D.G. (2006). Enhanced context-dependency of object recognition in rats with hippocampal lesions. Behavioural Brain Research, 170, 156-162.

O'Keefe, J., \& Nadel, L. (1978). The hippocampus as a cognitive map. Oxford: Oxford University Press.

Passos, M.C.F., Ramos, C.F., \& Moura, E.G. (2000). Short and long term effects of malnutrition in rats during lactation on the body weight of offspring. Nutrition Research, 20(11), 1603-1612.

Prestes-Carneiro, L.E., Laraya, R.D., Silva, P.R.C., Moliterno, R.A., Felipe, I., \& Mathias, P.C. (2006). Long-term effect of early protein malnutrition and growth curve, hematological parameters and macrophage function of rats. Journal of Nutritional Science and Vitaminology, 52, 414-420.

Reeves, P.G., Nielsen, F.H., \& Fahey, G.C. (1993). AIN-93 purified diets for laboratory rodents: final report of the American Institute Ad Hoc Writing Committee on the reformulation of the AIN-76 rodent diet. Journal of Nutrition, 123, 1939-1951.

Rice, D., \& Barone, S., Jr. (2000). Critical periods of vulnerability for the developing nervous system: evidence from humans and animal models. Environmental Health Perpectives, 108(Suppl. 3), 511-533.

Rossato, J.I., Bevilaqua, L.R.M., Myskiw, J.C., Medina, J.H., Izquierdo, I., \& Cammarota, M. (2007). On the role of hippocampal protein synthesis in the consolidation and reconsolidation of object recognition memory. Learning and Memory, 14, 36-46.

Santucci, L.B., Daud, M.M., Almeida, S.S., \& de Oliveira, L.M. (1994). Effects of early protein malnutrition and environmental stimulation upon the reactivity to diazepam in two animal models of anxiety. Pharmacology Biochemistry and Behavior, 49, 393-398.

Soares, R.O., Oliveira, L.M., Marchini, J.S., Antunes-Rodrigues, J., Elias, L.L.K., \& Almeida, S.S. (2013) Effects of early protein malnutrition and environmental stimulation on behavioral and biochemical parameters in rats submitted to the elevated plus-maze test. Nutritional Neuroscience, 16(3), 104-112.

Steckler, T., Drinkenburg, W.H.I.M., Sahgal, A., \& Aggleton, J.P. (1998). Recognition memory in rats: I. Concepts and classification. Progress in Neurobiology, 54, 289-311.

Suzuki, W.A., \& Eichenbaum, H. (2000). The neurophysiology of memory. Annals of the New York Academy of Sciences, 911, 175-191.

Valadares, C.T., Fukuda, M.T.H., Françolin-Silva, A.L., \& Almeida, S.S. (2010). Effects of postnatal protein malnutrition on learning and memory procedures. Nutritional Neuroscience, 13(6), 274282.

Wilson, D.I.G., Langston, R.F., Schlesiger, M.I., Wagner, M., Watanabe, S., \& Ainge, J.A. (2013). Lateral entorhinal cortex is critical for novel object-context recognition. Hippocampus, 23, 352-366.

Wolf, C., Almli, C.R., Finger, S., Ryan, S., \& Morgane, P.J. (1986). Behavioral effects of severe and moderate early malnutrition. Physiology and Behavior, 38(5), 725-730. 